\section{Arte e geopolítica: a lógica das interpretações*}

Glaucia Villas Bôas ${ }^{1}$

Resumo: $\mathrm{O}$ artigo tem o objetivo de discutir os critérios geopolíticos de classificação da arte, argumentando que tais critérios obstaculizam a apreciação das artes na sua dimensão estética e sociológica. Os critérios de natureza geopolítica se fundamentam em pares dicotômicos tais como exotismo vs. civilização, centro vs. periferia, nação vs. universalismo, que há mais de um século vêm sendo utilizados, por diretores de museus, historiadores, críticos de arte e curadores. Procura-se demonstrar o uso sistemático dessas categorias que servem tanto aos discursos críticos da pintura colonial quanto aqueles relacionados ao modernismo brasileiro. Conclui-se que somente o estudo das nuanças finas das interações entre os indivíduos e os grupos leva à compreensão da complexidade dos processos de criação artística, pondo fim aos constrangimentos das categorias geopolíticas de classificação e permitindo o trânsito em áreas ainda desconhecidas.

Palavras-chave: Arte, Classificação, Critérios Geopolíticos, Arte Brasileira.

A s interpretações canônicas da arte brasileira se fundamentam, com frequência, em critérios de natureza geopolítica. Ora a arte brasileira é considerada uma imitação da arte proveniente de centros europeus ou norte-americanos, ora privilegiam-se as singularidades constitutivas de sua identidade, a partir de diferenças históricas e culturais. Essa discussão não se evidencia apenas no campo das artes plásticas, mas é uma questão fundamental em todos os campos das humanidades e das ciências sociais ${ }^{2}$. Boa parte da produção intelectual e artística no Brasil se deve a esse dilema apaixonante que indaga - quem somos nós? A busca de uma cultura brasileira própria e singular, concomitante à inserção do país nos movimentos de universalização da cultura, estimulou uma produção notável, porém, em contrapartida, gerou categorias de classificação dos objetos culturais com base em fundamentos geopolíticos que não fazem jus à dimensão própria da arte, nem mesmo às práticas sociais voltadas para a criação artística, se seguirmos aqui uma perspectiva sociológica strictu sensu. As categorias centro/periferia, por exemplo, utilizadas muitas vezes para distinguir a produção cultural, estabelecem a priori uma relação de dominação e poder, relegando ao segundo plano as nuanças finas que definem a circulação e a interação de objetos e pessoas que geram trocas recíprocas, iguais, desiguais - por vezes, ao mesmo tempo, iguais e desiguais.

O debate sobre as singularidades e o universalismo da produção cultural
Recebido:

$15 / 06 / 2011$

Aprovado:

20/10/2011

* Uma versão deste artigo foi publicada em Third Text. Critical Perspectives on contemporary art \& culture, n. 114, 2012.

1. Professora da Universidade Federal do Rio de Janeiro, Departamento de Sociologia, Programa de Pós-graduação em Sociologia e Antropologia. E-mail:

glauciavboas@ gmail.com

2. Em Mudança Provocada. Passado e futuro no pensamento sociológico brasileiro, Rio de Janeiro, FGV (2006), argumento que a questão da identidade nacional e do universalismo é o problema que funda as ciências sociais no Brasil. 
não se limita, entretanto, às fronteiras do Brasil, ainda que nele tenha adquirido características próprias. Faz parte dos movimentos característicos da cultura ocidental europeia, o de universalização e padronização de um lado, o da distinção e da diferença de outro. Georg Simmel mostrou, com maestria, em seu ensaio sobre a moda (SIMMEL, 1986), como as tendências para a unidade e para a individualização estão presentes nas diversas dimensões da vida coletiva e individual, sem se ocupar, entretanto, dos aspectos históricos dessa questão. Contudo, a esse respeito, basta pensar na orientação do processo civilizatório liderado pela cultura europeia, desde a catequese cristã ao iluminismo, lembrar as críticas do movimento romântico ao iluminismo, ou, ainda, recordar a fase mais recente da globalização e projetos de transnacionalização em contraste com a ânsia de construção de identidades por todos os lados. A novidade encontra-se no atual questionamento dos cânones interpretativos pautados por essas dicotomias.

As recentes transformações tecnológicas, políticas e econômicas intensificaram as relações sociais em escala mundial, ligando localidades distantes e modelando acontecimentos locais através de eventos separados por muitas milhas de distância. A transgressão de fronteiras políticas, sociais e econômicas tem oferecido uma oportunidade única para a reatualização dos debates sobre o tema do universalismo versus diferenças históricas e culturais de caráter nacional, regional e local. Uma espécie de novo cosmopolitismo põe em movimento indivíduos e grupos pelas metrópoles e cidades, seja como viajantes ou navegadores da web, estimulando, paradoxalmente, uma crescente busca de identidade por coletividades diversas, seja pela sua etnia, gênero ou condições particulares de vida, a exemplo dos penitenciários (ZOLBERG et al., 1997).

Essas mudanças traduzem experiências individuais e coletivas que levam a questionar a validade dos cânones interpretativos, pondo em evidência, entre outras questões, os fundamentos geopolíticos para a classificação da arte nas bienais, atividades curatoriais, crítica e história da arte, organização de museus e exposições. Sem a pretensão de esgotar o assunto, questiono introdutoriamente, neste artigo, a validade dos critérios geopolíticos para a classificação das artes plásticas com vistas a uma revisão daqueles critérios, que considero prejudiciais para a apreciação da arte na sua dimensão simbólica e sociológica. Refiro-me ao caso brasileiro, apresentando exemplos ou modelos de classificação, cuja base está constituída pela oposição entre arte periférica e arte dos países centrais, presentes nas concepções e nas práticas de diretores de museus, historiadores, críticos de arte e curadores.

Intelectuais e artistas não têm se furtado aos debates sobre critérios de classificação das artes. Um exemplo que ilustra esse interesse refere-se aos debates resultantes das inovações ocorridas nas Bienais de São Paulo dos anos 
de 2004, 2005 e 2006. Nas 25a e 26a Bienais, seu curador, o alemão Alfons Hug, reagiu aos critérios geopolíticos utilizados para a seleção das obras, contestando a existência de uma arte periférica e posicionando-se a favor de uma arte cosmopolita. Muito embora tenha se empenhado em impor uma renovação dinâmica, Hug foi criticado pelas suas iniciativas. Em 2006, a 27a Bienal abandonou o sistema de escolha das obras por categorias nacionais, herança da Bienal de Veneza. A curadora Lisette Lagnado justificou sua iniciativa, afirmando que estava libertando a cultura de mecanismos geopolíticos que marcavam a burocracia cultural (ZOLBERG et al., 1997). Tanto o mundo "civilizado", quanto os representantes dos tribalismos emergentes se opuseram violentamente à posição de Lisette Lagnado. Os críticos também se opuseram veementemente aos conceitos inovadores e, apesar dos esforços para acabar com as categorias de núcleos históricos e representantes nacionais, a Bienal não logrou livrar-se por completo dos conceitos geopolíticos.

Essa problemática em discussão afeta diferentes dimensões do processo de criação artística, seu reconhecimento e consagração. No campo da arte, encontramse tanto os adeptos da internacionalização profunda da cultura e atribuição de um caráter universal à arte, como os defensores das culturais nacionais, locais e regionais. Contudo, o que acrescenta maior complexidade ao campo das artes plásticas e o distingue é o fato de que o debate sobre o universalismo versus as diferenças e singularidades da produção artística se faz em um momento em que o conceito de arte é questionado mais uma vez, com muita força. Basta lembrar a discussão de Raymonde Moulin sobre a mundialização do mercado de arte e, a partir dessa perspectiva, sua análise das mudanças que se operam em diversos níveis, incluindo novas funções para peritos, galeristas, curadores, diretores de museus, organizadores de exposições (MOULIN, 2007). Moulin acaba concluindo que a instabilidade e incertezas dos valores estéticos da arte contemporânea são incomparavelmente maiores do que no passado, quando a arte estava bem menos sujeita aos relativismos de toda espécie, o que atualmente concorre para que o reconhecimento e a consagração da obra de arte residam cada vez mais na avaliação dos especialistas e peritos do que em normas e convenções características de escola e estilos.

Nessa linha de orientação sobre a instabilidade atual do que seja uma obra de arte, Vera Zolberg vai mais longe, advertindo que o fim das hierarquias e das regras tradicionais do fazer artístico levou a inúmeros modos de se fazer arte, enfraquecendo a autoridade estabelecida do mundo artístico a tal ponto não ser mais possível saber o que é e não é arte (ZOLBERG et al., 1997). Essa condição histórico-sociológica, chamada pós-moderna, possibilitaria unicamente a análise do reconhecimento da arte das minorias ou outsiders - mulheres, loucos, prisioneiros, indígenas. 
Meu objetivo é, portanto, rever as categorias geopolíticas de classificação das obras de arte no Brasil, em um contexto no qual não somente o debate sobre o universalismo e a diferença está sendo revisitado, como também o debate sobre quem detém a autoridade para o reconhecimento e a consagração da obra de arte.

3. O Conde de Nassau foi contratado pela Companhia das Índias Ocidentais para assumir o governo civil e militar dos domínios holandeses conquistados na região nordeste do Brasil. Impondose militarmente aos portugueses, estabelecidos há mais de um século no lugar, Nassau permaneceu na cidade do Recife de 1637 a 1944, quando perdeu seu poderio militar para os portugueses. Administrou a produção de engenhos de açúcar, cuidou da defesa militar, além de incentivar $\mathrm{e}$ apoiar reformas urbanísticas na cidade de Recife. Tornouse conhecido pelo interesse na arte e na ciência, levando de volta à Europa um rico acervo de objetos e documentos impressos e iconográficos sobre as gentes, a fauna e a flora. Os pintores Franz Post e Albert Eckhout integraram a comitiva de Nassau.

\section{Significado do olhar estrangeiro}

No Brasil colonial (1500-1822), há, pelo menos, dois conjuntos de obras de arte de interesse dos críticos e historiadores da arte. São eles, a pintura holandesa, representada pelas obras de Albert Eckhout (1610-1665) e Frans Post (16121680 ), e o conjunto da arquitetura, escultura e pintura barroca que marcam o século XVIII. Esses conjuntos são, certamente, muito diferentes entre si no que respeita o volume e diferenciação dos acervos, a autoria, as funções e a dimensão estética. Contudo, enquanto nas pinturas de Eckhout e Post é considerado o olhar estrangeiro sobre a terra desconhecida, o barroco é enaltecido como uma das primeiras expressões da arte verdadeiramente brasileira. Percebe-se, desde já, que não importa a qualidade intrínseca das artes, porém, o território central ou periférico de sua proveniência e autoria.

Vou me deter, aqui, sobre a pintura de Eckhout. O acervo holandês tem origem na invasão da cidade de Recife, no nordeste brasileiro, pelo Conde Johan Maurits van Nassau-Siegen, empregado da Companhia das Índias Ocidentais, que se tornou Governador Geral do Brasil Holandês, de 1637 a $1644^{3}$. Nassau promoveu a criação de um acervo importante de pinturas e desenhos que retratam paisagens, fauna, flora e habitantes do país. Ao final da dominação do conde holandês, as obras voltaram para a Europa e foram presenteadas ao rei da Dinamarca por Nassau. Depositadas no Real Kunstkammer, por volta de 1650, pertencem à coleção etnográfica do Museu Nacional de Copenhagem. Em 2002, depois de 350 anos, as telas de Eckhout voltaram ao Brasil para exibição.

A leitura do catálogo Albert Eckhout returns to Brazil, 1644-2002 demonstra que os painéis de Eckhout, pintados a óleo sobre tela de linho, retratando índios, mamelucos, negros, homens, mulheres, frutas, flores e raízes, se transformam em objeto de classificação rigorosa e precisa, cujo princípio organizador é o exotismo (EKHOUT, 2002). Concebidas in loco, a partir da observação direta, as pinturas são definidas como registros etnográficos de tipos étnicos, fauna e flora. Considerando-se que a função do pintor consistia em retratar o que não havia sido visto antes pelos europeus, o que mais interessa aos artigos do catálogo é a história do acervo, as técnicas de sua conservação, o inventário dos trabalhos, a certificação da autoria com o objetivo de garantir a veracidade das pinturas para sua 
utilização pela ciência e pela história. As pinturas dos tipos étnicos, surpreendentes pelo tamanho das telas, em média de $265 \mathrm{~cm} \times 165 \mathrm{~cm}$, assim como a expressão fisionômica dos retratados, não são analisadas, tampouco referidas à história da arte ocidental. Toda a apreciação da pintura está aqui limitada às fronteiras do exótico, do desconhecido e do inominável.

É indiscutível que o zelo técnico pela conservação e estudos sobre a técnica do pintor sejam indispensáveis para a manutenção do acervo. Essas obras têm sido objeto de pesquisa ultimamente, devido, sobretudo, à valorização das histórias de viagens e sua contribuição para a descoberta de uma miríade de fatos que levam a rever as interpretações convencionais sobre as mudanças operadas no mundo ocidental, geralmente compreendidas nos limites dos marcos da revolução industrial e do iluminismo, vistos como os motores fundamentais das transformações. Porém, o que chama atenção nos discursos do catálogo é a quase impossibilidade de apreciação da pintura de Eckhout de qualquer outra perspectiva que não seja etnográfica e que permita apreciar dados como composição, cores, textura, movimento, assim como avaliar as práticas de criação artística em sua diversidade ao longo do tempo.

Como mostra o trabalho de Peter Mason, o inventário do Real Kunstkammer da Dinamarca conferiu novo nome para os quadros de Eckhout em 1991, denominando-os retratos (MASON apud ECKHOUT, 2002). Mason pergunta-se, então, se é possível haver retratos etnográficos e demonstra a maneira engenhosa como o pintor holandês usava objetos de outros lugares - como da Ásia e da África -, que haviam sido trazidos como curiosidades para o Brasil, para adornar seus retratos e proporcionar o mise-en-scène às suas pinturas. Contrariando as concepções mais habituais e evocando o trabalho etnográfico de fotógrafos, Mason defende que a coisa etnográfica não existe como tal, mas é construída com deslocamentos de objetos e técnicas para mostrar as diferenças entre europeus e não europeus, resultando em uma montagem maravilhosa. A proposta de Mason quebra com a ideia da pintura como registro visual preciso que busca demarcar de modo persuasivo as diferenças, propondo que sejam concebidas como construção da visualidade do exótico.

Não seria possível, aqui, inventariar os trabalhos críticos de autores brasileiros sobre a obra de Eckhout, mas é minha intenção contrastar as categorias utilizadas pela crítica veiculada na grande imprensa paulista com os artigos publicados no catálogo Albert Eckhout returns to Brazil, 1644-2002, por ocasião das exposições dos painéis do pintor holandês na cidade. É interessante verificar que os comentários publicados na imprensa ressaltam o fato de que Eckhout pintou indígenas, negros e mamelucos de acordo com o grau de civilização que apresentam a partir de sua indumentária: quanto mais vestidos, mais civilizados, uma vez que a nudez é condenada pelas convenções sociais. O grau de 
4. Jotabê Medeiros. Jornal O Estado de São Paulo 24.01.2003

5. O barroco é arte religiosa e católica feita no Brasil. É obra das irmandades laicas, dos mestiços e escravos livres que aprenderam com os mestres de ofícios trazidos pelos portugueses, padres seculares e monges das ordens religiosas, muitos deles viajantes, que haviam estado em Goa e Macau, além de outras colônias portuguesas. civilização se apresentaria, também, no tipo de fundo onde se projeta a figura. Se o fundo retrata a natureza, o grau de civilização apresentado na tela é menor do que um painel cujo fundo mostra uma edificação. A apreciação da tela varia, portanto, de menor para maior grau de civilização. A utilização da categoria civilização para apreciação das telas tem como objetivo mostrar que, mesmo em terras exóticas e colonizadas, há possibilidade de construção de uma nação. E, nesse caso, trata-se de confirmar aquela possibilidade através de um olhar estrangeiro que vem do centro civilizado. Sem deixar naturalmente de qualificar a colonização como fenômeno violento, o crítico do jornal O Estado de São Paulo afirma que,

(...) o pintor holandês mostrava os detalhes de uma nação surgindo da mistura, da simbiose, uma terra que se moldava às exigências da colonização brutal e veloz. São retratos do deslocamento: o colar de pedras preciosas na mulher mameluca descalça. ${ }^{4}$

Podemos, agora, refletir sobre as categorias utilizadas nos discursos que circularam por ocasião da volta das telas de Eckhout ao Brasil, em 2002. As ideias de civilização e exótico não estão distantes, se vistas no âmbito de um processo civilizatório da cultura ocidental. No discurso do catálogo, o exótico se contrapõe ao civilizado com poucas possibilidades de aproximação. Porém, na crítica brasileira, o exótico objeto de conquista alheia pode se misturar com o civilizado e alcançar algum grau de civilização. Joga-se, aqui, com a construção histórica das periferias exóticas e com a sua condição de maleabilidade, plasticidade e mistura. Note-se que tanto os civilizados, quanto os exóticos têm territórios bem delimitados, encontrando-se apenas em espaços geográficos definidos por uma política de colonização. Vistas como registros etnográficos descritivos, as pinturas de Eckhout estão destinadas a uma apreciação fechada em um círculo de ferro. Tal situação assemelha-se à impossibilidade de apreciar, como arte, as pinturas de esquizofrênicos do Ateliê do Engenho de Dentro no Rio de Janeiro, após sua integração ao acervo do Museu das Imagens do Inconsciente, em meados do século passado, devido à sua importância documental para a ciência e a terapêutica, como mostramos em outro trabalho (VILLAS BÔAS, 2008).

Ainda que não tenha o objetivo de proceder à análise da crítica do barroco, vale a pena ressaltar como críticos e historiadores da arte avaliam positivamente sua brasilidade, transformando a arte barroca em uma conquista da periferia em contraste com o olhar estrangeiro do centro. Um vasto conjunto artístico que se espalha por diversas cidades, o barroco ${ }^{5}$ do do período colonial abarca a escultura, a pintura e a arquitetura feitas no Brasil no século XVIII, cuja valorização ocorre na década de 1930 e está fortemente relacionado com a criação do Serviço do Patrimônio Histórico e Artístico Nacional, órgão governamental, ao qual se atribuiu a tarefa de guardar e zelar pelo patrimônio artístico e cultural. Diga-se que, justamente quando surge o modernismo, na década 
de 1930, como veremos mais adiante, ganha importância entre intelectuais, artistas e políticos a memória da produção cultural brasileira. O arquiteto Lucio Costa, responsável pelo plano piloto da cidade de Brasília, foi um entusiasta da arte barroca, estimulando sua preservação. Via no barroco brasileiro, com sua aliança entre singeleza e monumentalidade, uma expressão autêntica, livre do rótulo de imitação:

Há certa tendência a considerar imitações de obras reinóis as obras e peças realizadas na colônia. Na verdade, porém, são obras tão legítimas quanto as de lá, porquanto o colono, par droit de conquête, estava em casa, e o que fazia de semelhante ou já diferenciado era o que lhe apetecia fazer - assim como ao falar português não estava a imitar ninguém, senão a falar, com sotaque ou não, a própria língua. (COSTA, 2003, p. 40)

A crítica de Costa não ignora a ideia de atraso, uma vez que o barroco teria surgido, no Brasil, cem anos após o barroco italiano, espanhol e holandês. No entanto, o autor enfatiza a brasilidade do barroco - algo feito no Brasil e próprio de sua identidade. Nesse caso, a crítica abandona a ideia de civilização para insistir na ideia de uma arte autóctone com expressão artística própria.

\section{Os dois programas estéticos do modernismo}

O uso dos critérios geopolíticos de classificação da arte se acentua na crítica modernista. O modernismo no Brasil tem duas faces ou programas estéticos: um figurativo, outro construtivista. O primeiro volta-se para a representação dos retratos do Brasil, nas décadas de 1920 e 1930 . A renovação da linguagem artística vincula-se a um programa político de construção da nação, no qual a busca da brasilidade através das origens da arte popular, indígena e negra é fundamental. Esse primeiro programa estético do modernismo brasileiro não acompanha os movimentos de vanguarda do início do século, como o suprematismo ou futurismo, mas é, antes de tudo, um importante movimento de inspiração expressionista ou cubista que, além de almejar a representação das origens étnicas brasileiras, quer retratar os hábitos e os modos de vida do povo pobre, ressaltando as paisagens rurais, urbanas e suburbanas típicas de regiões do país.

Em suas disputas pelo reconhecimento e legitimidade, o modernismo escoIheu como alvo de sua crítica o academicismo da Escola Nacional de Belas Artes, que se chamava Escola Real de Ciências, Artes e Ofícios, quando foi criada pelo rei de Portugal, em 1816, pouco depois da chegada da corte portuguesa ao Rio de Janeiro e Academia Imperial de Belas Artes, no período de 1922 a 1889. À Academia coube o importante papel de iniciar o ensino regular da 
6. O Salão Nacional de Artes Plásticas de 1931, organizado por Lucio Costa como diretor da Escola Nacional de Belas Artes é um dos melhores exemplos da polêmica entre modernistas e acadêmicos e deslocou o lugar privilegiado do academicismo, partindo da própria Escola. A exposição causou polêmica porque separou os quadros dos modernistas, cujas obras foram dispostas individualmente nas paredes, o que não ocorreu com os acadêmicos cujos quadros pendurados uns sobre os outros impediam o foco da visão em um deles. Ver a respeito do Salão de 1931, em Vieira (1984)

7. A Associação Brasileira de Críticos de Arte foi criada em 1949, vinculada à Associação Internacional de Críticos de Arte, criada pela UNESCO, após a segunda guerra mundial, que, ao longo de mais de meio século, encorajou a troca e o debate intelectual sobre arte. pintura acadêmica no país, predominando suas regras ao longo do século XIX, durante a independência e o império. Como resultado dessa iniciativa, reuniram-se obras de estrangeiros e brasileiros em acervo constituído pela pintura histórica, paisagens urbanas, retratos da corte, indivíduos ilustres, cenas da vida prosaica e cotidiana. À academia é atribuída a formação de uma visualidade nova, indispensável à construção da nação independente de Portugal criada em 1822.

Contudo, a crítica modernista foi tão severa com relação à pintura acadêmica a qual combatia como uma imitação grosseira do neoclassicismo europeu, que somente em 2008, durante as comemorações dos 200 anos da vinda da corte portuguesa ao Brasil, foi possível restaurar, exibir peças do acervo, publicar análises críticas, enfim, reavivar a memória da escola que até hoje funciona como órgão da Universidade Federal do Rio de Janeiro, tendo há muito tempo perdido seu caráter academicista. Na realidade, a crítica modernista ao academicismo reproduz a lógica das críticas que mencionamos anteriormente, ao fazer uso da categoria imitação para demonstrar a falta de autonomia dos pintores acadêmicos com relação a uma orientação existente em centros europeus, que começara a ser questionada. Nesse caso, diferentemente de outros, a imitação foi vista como negativa, mas o fundamento da estrutura argumentativa, o par centro/ periferia, permanece sem alteração. A vitória do modernismo, finalmente, se deve, na sua primeira fase e programa, além de outros fatores, ao Estado brasileiro que, na década de 1930, interessado na construção de uma identidade nacional, incorporou e oficializou os artistas modernos, a exemplo de Cândido Portinari e Di Cavalcanti, consagrando o modernismo dos retratos do Brasil ${ }^{6}$.

O reconhecimento da linguagem modernista nas artes plásticas está inscrito nos textos de críticos e de historiadores da arte que, a partir do período do pósguerra, ganharam um estatuto diferenciado, afastando-se dos meios literários strictu sensu e passando a ser escritos por especialistas em artes plásticas. Apesar dessa mudança, que decorre de fatores tão diversos como a criação da universidade e de um público universitário, a circulação de jornais matutinos e vespertinos nas grandes capitais e a criação da Associação Brasileira de Críticos de Arte $^{7}$, a análise do modernismo nas suas duas versões figurativa e construtivista persiste no uso de categorias geopolíticas. O eixo da crítica do modernismo nas artes plásticas é o confronto entre padrões estéticos voltados para a construção da identidade nacional e os padrões estéticos de caráter universal.

Esse modelo interpretativo aparece tanto em trabalhos que abordam o sentido das obras, como nas pesquisas sobre os efeitos dos movimentos de vanguarda. No primeiro caso, quando o sentido está em jogo, busca-se a presença da nacionalidade nas obras, sobretudo naquelas vinculadas ao primeiro programa modernista que se inaugura em 1920, contrapondo-se à ausência de 
brasilidade das obras concretistas dos anos 1950. Analisando os movimentos de vanguarda na América Latina, Ana Maria Belluzo afirma que o abandono dos cânones acadêmicos pela pintura, nos anos de 1920, possibilitou aos artistas uma visão inédita que singulariza a pintura modernista daquele período (BELLUZZO, 1990). A Negra, pintada por Tarsila do Amaral, em 1923, e Abaporu, em 1928, seriam exemplares da centralidade do mito de origem na pintura vanguardista brasileira do período. Afirma a autora que, naquela pintura,

(...) a dimensão poética desvenda um tempo imaginário fora da modernidade, anterior à história. $\mathrm{O}$ retorno ao tempo original reinventa o passado e revive o mito da criação, como mito da fundação e da origem, como fundamento da arte. (ibidem, p. 23)

Ao contrário, a interpretação do sentido das obras de Waldemar Cordeiro, Ivan Serpa, Lygia Clark, Lygia Pape, que aderiram ao construtivismo nos anos de 1950, fazendo parte dos movimentos concreto e neoconcreto, ressalta as conexões de sentido das obras com a construção de uma sociedade industrial moderna:

(...) a clara divisão entre projeto e obra, as operações seriadas, a cor plana, a economia de elementos de produção do quadro e do objeto, os estudos da forma e da contraforma, a concepção de obra múltipla não escondem a elaboração da estética industrial. Mesmo que não estivessem ajustadas adequadamente ao estágio de desenvolvimento da produção entre nós e se antecipassem a ela. (ibidem, p. 28)

Nem o "viés cubista", nem o concretismo contém em si uma qualidade através da qual fosse possível associá-los, sem mediações, com a construção da identidade nacional ou com valores típicos do universalismo característico de uma sociedade moderna industrial. Tanto é que a criação de sentido nacional para as obras modernistas de 1920 é qualificada como uma visão inédita dos artistas plásticos brasileiros; no segundo caso, relativo ao universalismo típico da sociedade industrial moderna, os estudos verificam que a sociedade brasileira almejava tornar-se uma sociedade moderna, mas não o era ainda, havendo um desajuste entre a obra e o contexto de sua produção. Ao classificar a produção artística em duas amplas orientações, essas abordagens privilegiam o envolvimento de artistas e intelectuais na criação de sentido de caráter político e social em que pesem as ressalvas relativas às nuanças e diferenças. Diga-se, ainda uma vez, que tais modelos explicativos dos dois modernismos brasileiros não são privilégio das análises das obras ou dos movimentos artísticos, mas frequentemente utilizados nas interpretações da produção brasileira cultural.

Outra modalidade interpretativa do modernismo artístico brasileiro procura reconstituir o caminho das influências dos movimentos de centros europeus 
8. Ver sobre esse viés interpretativo em Osório (2010) nos meios artísticos brasileiros. Em uma de suas orientações, tal modalidade retoma a ideia da origem das mudanças, atribuindo à força dos movimentos das vanguardas internacionais as modificações das regras, das concepções estéticas e dos valores artísticos. O modernismo dos anos 1950 é compreendido, por exemplo, pela influência que sobre ele teriam exercido os movimentos do Suprematismo, De Stijl, Cercle et Carré, Bauhaus, que pregavam novas concepções do trabalho artístico em diferentes países europeus. As vanguardas brasileiras teriam se constituído a partir de possibilidades abertas pelas vanguardas europeias, contribuindo para aguçar as contradições entre o centro e a periferia.

A abordagem histórica e social desdobra-se em uma segunda direção, quando argumenta que as mudanças no programa estético modernista dos anos 1950 são decorrentes das transformações econômicas que levaram à consolidação da indústria no país e à racionalização das condutas na esfera econômica, social e política. O que está em jogo agora é uma relação necessária entre a sociedade industrial e a arte funcional, adequada e integrada nos diversos ambientes onde vivem indivíduos e coletividades. O Brasil vivia um período de transformação rápida de sua estrutura econômica. A renovação da linguagem artística seria, sob essa ótica, um efeito das mudanças aceleradas no modo de produção econômico, ainda que a sociedade industrializada trouxesse certa autonomia para a esfera da arte (BRITO, 1999). Tal relação de necessidade explicaria as mudanças da arte figurativa para a arte concreta, assim como o fim da identidade romântica dos artistas. O programa estético modernista dos anos de 1950 põe em discussão o papel social dos artistas, acirrando a crítica de arte, as disputas e os conflitos entre os integrantes dos dois modernismos. Tornou-se um momento decisivo da arte brasileira cuja poética poderia considerada uma contribuição ao surgimento da moderna cultura visual ${ }^{8}$.

A produção da história e crítica da arte foi e é indispensável para o entendimento da constituição daquele período da história da cultura no país. Contudo, apesar das diferenças conceituais notáveis que distinguem alguns dos especialistas que delas se ocuparam, pode-se dizer que a recepção de seus trabalhos confere grande relevância aos processos sociais de construção da identidade nacional e de construção da sociedade moderna através das artes plásticas. Em decorrência desse viés analítico, a exigência do engajamento dos artistas em um programa político e social permanece inalterada, dificultando a renovação e a experimentação na atividade artística. Finalmente, as relações de determinação entre centro e periferia, bem como entre o contexto social e valores artísticos, tornam-se naturais, como se a ação e interação entre os indivíduos e grupos não desempenhasse um papel sem o qual a criação artística seria impossível.

A atuação do crítico brasileiro Mario Pedrosa no interior da Associação Internacional de Críticos de Arte, no período de 1949 a 1959, mostra que a classificação 
de obras de arte de acordo com sua procedência nacional não é qualidade da crítica brasileira, mas da crítica internacional. O melhor exemplo para demonstrar tal afirmação está na dimensão discursiva do I Congresso Extraordinário de Critica de Arte que ocorreu no Brasil nas cidades de Brasília, São Paulo e Rio de Janeiro, em 1959 (LOBO et al. 2009). O Congresso proposto por Mario Pedrosa para discutir a cidade de Brasília e a Integração das Artes reuniu naquelas três cidades críticos de renome internacional, como Giulio Carlo Argan, Meyer Shapiro e Tomás Maldonado, entre outros. Uma análise dos anais do evento evidencia que nenhum dos críticos estrangeiros se referiu à cidade de Brasília fora da referência da história das cidades europeias ou de quadros de referência conceituais que não se aproximavam nem de perto às formulações ${ }^{9}$ sobre a cidade novíssima que tinham sob seus olhos. Os jogos classificatórios que, ao longo do tempo, marcam a crítica brasileira pela utilização das categorias de natureza geopolítica não foram ainda abordados criticamente. Ao contrário, as mudanças que se operam, sobretudo, no mercado de arte, estimulam a sua classificação por territórios. Ela permanece na ordem do dia. Mas as pesquisas históricas e empíricas evidenciam a complexidade do problema. Quantos artistas brasileiros saíram do País e foram para o "estrangeiro", em busca de maior conhecimento, e quantos estrangeiros vieram para o Brasil e aqui fixaram residência, tornando-se "brasileiros"? Quantas missões artísticas francesas vieram ensinar aos brasileiros? E qual a repercussão da arte brasileira em países ou cidades estrangeiras? A circulação regular e constante de artistas e objetos põe definitivamente em questão os critérios geopolíticos e contribui para descortinar disputas e tensões constantes entre indivíduos e grupos, qualquer que seja sua procedência. Os indivíduos e grupos voltados para a criação artística integram uma rede social cosmopolita com regras e autoridade própria. Tal dimensão da vida social inclui não somente a atividade artística em si, mas também o aprendizado da arte, professores, escolas, exposições, galerias, museus, o mecenato privado e estatal, a crítica de arte, curadoria, peritos, restauradores, meios vários de comunicação, público, mercado. Somente um estudo das nuanças finas das interações entre os que são chamados de civilizados ou nativos, habitantes de centros ou de periferias levaria à compreensão da complexidade dos processos de criação artística, libertando as obras dos limites de categorias classificatórias geopolíticas e permitindo seu trânsito em zonas ainda desconhecidas.

Abstract: The article explores the use of geopolitical criteria as a method for classifying art, so as to revise criteria considered prejudicial to the appreciation of art in its symbolic and sociological dimension. With reference to Brazilian art, it presents classification models that are based on dichotomies such as exoticism vs. civilization, centre vs. periphery and nation vs. universalism, these models have informed museum directors, historians, art critics and curators, for more than a century. Those dichotomies are analysed in critical discourses from colonial paintings as well as those related with Brazilian
9. Tais formulações, inscritas no projeto de Lucio Costa para a nova capital, acentuavam a concepção da cidade como um ato de posse, um gesto de sentido, caracterizado por um risco original simples de dois eixos cruzando em ângulo reto, sem prejuízo da variedade no tratamento das partes da cidade segundo suas funções, o que levava à uma unidade harmônica contraditória (COSTA, 2003, p. 117-145). Para meIhor compreender o debate havido no I Congresso Extradordinário de Críticos de Arte sobre a cidade de Brasília ver: Costa (2003), Lobo (2009), Arantes (2004) e Pedrosa (1981). 
modernism. It concludes that only a study of the finer nuances of the interactions between individuals and groups can lead to the comprehension of the complexity of artistic creation processes, breaking free from the constraints of geopolitical classification categories and permiting its transit through yet unknown areas.

Keywords: Art, Classification, Geopolitical Criteria, Brazilian Art.

\section{Referências Bibliográficas}

ARANTES, Otília B. et al. Itinerário crítico. São Paulo: Cosac Naify, 2004.

BELLUZZO, Ana Maria de Moraes (Ed.) Vanguardas artísticas na América Latina. São Paulo: Editora da UNESP, 1990.

BRITO, Ronaldo. Neoconcretismo: vértice e ruptura do projeto construtivo brasileiro. São Paulo: Cosac Naify, 1999.

COSTA, Lucio. Arquitetura. Rio de Janeiro: José Olympio Editora, 2003.

ECKHOUT, Albert. Albert Ekchout returns to Brazil, 1644-2002. Copenhagen: Nationalmuseet, 2002.

LOBO, Maria da Silveira e SEGRE, Roberto (Eds.) "Cidade Nova: Síntese das artes". Congresso Internacional Extraordinário de Críticos de Arte. Rio de Janeiro, Universidade Federal do Rio de Janeiro, Faculdade de Arquitetura e Urbanismo, 2009.

MASON, Peter. "Oito grandes quadros com pessoas das Índias Orientais e Ocidentais. A Montagem maravilhosa de Albert Eckhout". In: A. Eckhout, Albert Ekchout returns to Brazil, 1644-2002. Copenhagen: Nationalmuseet, 2002, p. 148.

OSORIO, Luiz Camillo. "Das Verlangen nach Form und die Formen des Verlangens: der Neokonkretismus als einzigartiger Beitrag der brasilianischen Kunst". In: R. Kudielka, A. Lammert, L. C. Osorio (eds.) Das Verlangen nach Form. Neoconcretismo und eitgenoessische Kunst aus Brasilien. Berlin: Akademie der Kuenste, 2010.

PEDROSA, Mario. Dos Murais de Portinari aos espaços de Brasília, São Paulo: Ed. Perspectiva, 1981.

SIMMEL, Georg. Philosophisher Kultur. Berlin: Verlag Klaus Wagenbach, 1986, p. 38-40. 
VILLAS BÔAS, Glaucia. "A Estética da conversão: o ateliê do Engenho de Dentro e a arte concreta carioca, 1946-1951". Tempo Social, vol. 20 n. 2, São Paulo, novembro, 2008.

VIEIRA, Lucia Gouvêa. Salão de 1931. Marco da revolução da arte moderna em nível nacional. Rio de Janeiro: Funarte, 1984.

ZOLBERG, Vera; CHERBO, Joni Maya (Eds.) "Outsider art: contesting boundaries". Contemporary Culture. Cambridge: Cambridge University Press, 1997 